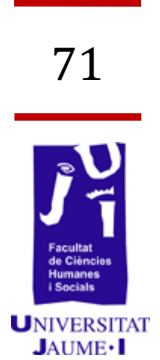

\title{
La concepción del ser humano y la religión en la teoría filosófica kantiana
}

Maria Medina-Vicent medinam@uji.es

m.medinavicent@gmail.com 
En el seno de la línea de investigación del presente trabajo nos interesa abordar un tema central para la comprensión del ser humano en todas sus dimensiones. Qué es el individuo antropológicamente hablando, cuáles son las bases de su conducta y modos de organización social. Por otra parte, también resulta importante comprender qué supone la religión para dicho ser, porqué existe en su interior la necesidad de fundamentar su conducta en base a la existencia de un Ser Supremo que guía sus acciones y decisiones. Como vemos, se trata de dos temas de gran importancia para la comprensión del devenir de la vida humana. Dos temáticas que intentaremos tratar inicialmente por separado, pero que se irán interrelacionando a lo largo del texto de forma inevitable, y es que como el propio significado del término religión nos indica (religare), hay que unirlo todo en un sentido de la vida unificado.

Palabras clave: racionalismo, imperativo categórico, fe racional, fe estatutaria, iglesia universal, iglesias particulares.

\section{Introducción y Objetivos}

Con este escrito se pretende llevar a cabo una aproximación a la perspectiva kantiana, haciendo especial hincapié en la teoría filosófica que desarrolló dicho autor acerca de la religión y del comportamiento del ser humano. Antes de adentrarnos en las reflexiones de Kant acerca de la religión, debemos de ser conscientes de que éste no parte ni de una posición naturalista, que niega cualquier tipo de revelación; ni de una posición sobrenaturalista, que declara la necesidad de una revelación dentro de las distintas religiones. De otra manera, Kant determina su propio pensamiento filosófico llamándolo "puro racionalismo», una línea de argumentación que admite la revelación pero no la considera necesaria para practicar la verdadera religión, que sería la religión de la moralidad (Hottois, 1999).

Así pues, Kant va a restablecer la teología como un saber que está íntimamente ligado a la reflexión sobre la moral y que encuentra en dicha dimensión su propia legitimación (Quintana Cabanas, 1989). Y es que resulta clave reconocer que el sentimiento de religiosidad forma parte del ser humano, no obstante, a la hora de abordar su estudio antropológico, deberemos tener en cuenta que no vamos a analizar la esencia de la religiosidad en sí misma, sino las funciones que subyacen a un fenómeno que es parte irrenunciable de la naturaleza humana.

En resumen, a lo largo de este trabajo nos espera un intenso viaje entre las pasiones y las virtudes de los seres humanos, entre sus miedos y aspiraciones, y sobre todo la necesidad de la religión para poder poner en práctica su razón. Así pues, una de las claves a la hora de abordar nuestro estudio es reconocer que la religión tiene una función de integración social 
(Cabedo, 1997: 35), rasgo que va a permitir conformar comunidades justas para los seres humanos, al mismo tiempo que conductas buenas entre ellos.

\section{Material y método}

La metodología de la que se nutre este trabajo de investigación se centra en una revisión crítica del pensamiento filosófico de Immanuel Kant, centrado en la antropología filosófica de la religión y el ser humano en sus obras: La religión dentro de los límites de la sola razón (1793), Fundamentación para la metafísica de las costumbres (1785) y Sobre la paz perpetua (1795).

\section{Breve aproximación a la filosofía kantiana}

Antes de adentrarnos en el estudio de la obra La religión dentro de los límites de la sola razón (1793) del filósofo Immanuel Kant (1724-1804), daremos un repaso a su filosofía para poder comprender con mayor facilidad las ideas que desarrolla en dicha obra. Kant desarrolló su trabajo en el marco de la llustración, periodo de la historia intelectual de Europa caracterizado por la puesta en valor del ejercicio de la razón humana y la fe en el progreso. Dicho contexto supuso un cambio trascendental para la historia del pensamiento europeo así como para el humano en general, que empezó a basarse en la idea de que la luz de la razón era la herramienta idónea para disipar las tinieblas de la mitología y la incomprensión que habían sepultado a la Humanidad a una situación de ignorancia generalizada. Como diría el propio Kant, la llustración supondría «la salida del hombre de su minoría de edad» (Kant, 1785).

Con su obra Fundamentación para la metafísica de las costumbres (1785), Kant trabajó la idea de la búsqueda de un principio universal que gobernase la moral, surgido del ejercicio de una razón autónoma. Así pues, mediante el uso de la razón se puede llegar a un principio universal exigible a todos, un principio que adoptaría la forma del «imperativo categórico». Pero, ¿cómo llegar a definir o establecer dicho principio? En este orden de cosas, Kant destaca el hecho de que sería imposible obtener leyes morales universales a partir de experiencias concretas, pues ninguna experiencia puede ser una fuente de principios morales aplicable a todos los casos. Por tanto, si la ética pretende ser universal deberá ser formal y constituida a priori, es decir, poseer contenido desprovisto de las experiencias particulares, ya que su único pilar ha de ser la razón, que permite universalizar la máxima moral de las acciones.

En relación, Kant no concibe el concepto de Dios como un concepto basado en la experiencia, sino más bien en nuestra idea a priori de la perfección moral. Por consiguiente, se especifica que la razón aborda leyes acerca de la moral. Sin embargo, Dios sería un anhelo o una evidencia moral sin ninguna certeza científica, que sirve para guiar nuestras 
obligaciones morales y concebirlas como deberes divinos que cumplir en el accionar de nuestra vida diaria. Además, la visión que tenemos de Dios proviene de nuestra idea de la perfección moral, lo cual nos sirve de base para empezar a entrever la idea de religión que desarrollaremos más adelante con Kant.

En cuanto a los seres humanos, son capaces de hacer uso de su razón práctica, de seleccionar la acción más correcta indistintamente de los estímulos, pasiones, necesidades u obligaciones de las sensaciones de satisfacción o insatisfacción. Por tanto, se trata de individuos capaces de enderezar su voluntad, ya sea con las leyes objetivas de la razón y moralidad, o bien con las necesidades subjetivas e intereses. Consecuentemente, observamos que la filosofía de Kant basa la moral en razones que puedan ser válidas para todos los seres racionales.

Por otro lado y adentrándonos ya en el tema que nos ocupa en el presente trabajo, La religión dentro de los límites de la sola razón (1793) es una de las críticas más feroces que se ha llevado a cabo nunca «contra todas las religiones positivas y reveladas, incluida la religión cristiana» (Quintanta, 1989: 10). Kant no discute sobre la existencia o no de Dios, lo que hace es «llevar a cabo una admisión problemática (hipótesis) de su existencia, basta con la idea (mera idea regulativa) de Dios, y debe evitarse el tratar de demostrar teóricamente su existencia» (Quintana Cabanas, 1989: 11). La fe racional a la que apela Kant supone que el saber de la religión es ejercicio de la libertad, por tanto, vemos que para Kant la religión no escapa de su campo filosófico de reflexión. En esta línea, resulta de gran importancia destacar que Kant desea encontrar «el sentido que para el ser humano tienen o deben tener sus actos religiosos tanto a nivel de experiencia personal, como de práctica colectiva» (Cabedo, 1997: 39).

En resumen, Kant desarrollará sus ideas a partir de los fundamentos griegos y abrirá paso a la filosofía moderna, dando lugar a ideas que aún siguen claves hoy. Por tanto, la filosofía kantiana supondrá un antes y un después en el pensamiento moderno, porque sienta las bases para el uso de la plena razón y abre las puertas a la determinación de los Derechos Humanos. Además, sus tres principales obras son consideradas a menudo como el punto de partida para las distintas ramas de la filosofía moderna: Crítica de la razón pura (1781) para la filosofía de la mente, Crítica de la razón práctica (1788) para la filosofía moral, y Crítica del juicio (1790) para la estética y filosofía del arte. 
PRIMERA PARTE: EL SER HUMANO

\section{Entre el principio del bien y del mal.}

Cuando empezamos a estudiar al ser humano en sus interrelaciones con otros/as, las organizaciones sociales y sus comportamientos, siempre nos acercamos a una cuestión clave: ¿Cuál es la naturaleza del ser humano? ¿Está basada en la bondad o en la maldad? Así, el debate acerca de la naturaleza del individuo es amplio y antiguo, una cuestión esencial para empezar a hablar del ser humano y la religión. La primera clave reside en ser conscientes de que cuando se reconoce que el ser humano es bueno o malo por "naturaleza», se puede caer en una ontologización que atenta contra las bases racionales del comportamiento humano. Es decir, si entendiésemos por "natural» aquello que nos viene dictado de forma externa y que no es posible cambiar, estaríamos refiriéndonos a algo que escaparía a nuestro libre albedrío. Por tanto, llevar a cabo esta afirmación supone atentar contra una de las ideas básicas de la filosofía kantiana, es decir, afirmar que el ser humano no es libre y que es malo o bueno por algún condicionante innato contra el que no puede luchar, ataca a la libertad y el carácter racional de la Humanidad.

En consecuencia, esta idea supone la afirmación de que el ser humano no puede hacer nada para cambiar su naturaleza y por eso se deja llevar sin tener en cuenta los fines de sus acciones, un hecho que supondría actuar inmoralmente. Ni mucho menos, con Kant vemos que el ser humano lo es por su capacidad para deliberar, para discernir la corrección de sus actos y actuar conforme a la ley moral universal. Cualquier otra cosa no sería propiamente un ser humano racional.

Además, no se trata ya tanto de que la Humanidad sea por naturaleza buena o mala, sino de que cada individuo se encuentra en posesión de unas inclinaciones hacia el mal y hacia el bien, "pero esto no hace todavía al hombre bueno o malo, es tomando libremente por máxima suya el bien o el mal como el hombre se hace a sí mismo bueno o malo» (Quintana Cabanas, 1989: 7). Es decir, no hace malo al individuo su naturaleza, sino su decisión racional tomada libremente de escoger como máxima de su acción el deber o la maldad. En este orden de cosas, todo aquél que se aparte del sendero de la razón y que no tenga entre sus acciones el deber como fin superior, pondrá en práctica acciones inmorales que no ayudarán a la conformación de una sociedad justa.

Dentro de este debate, Kant afirma que el individuo tiene una tendencia a escoger el mal, porque al llevar a cabo sus acciones «subordina los motivos morales a otros motivos secundarios» (Quintana Cabanas 1989: 7). A partir del reconocimiento de las personas como seres inclinados a obedecer su pretensión al mal, se desprende una lucha interna de dichas personas para actuar conforme a la moral. Se trata de una batalla que sólo 
podrá ser ganada por el ser humano cuando éste convierta su actuar conforme al deber en una obligación moral que sepulte todos los demás móviles de sus acciones.

\subsection{La lucha del ser humano contra su propensión al mal}

Como se ha comentado anteriormente, coexisten en la naturaleza humana el principio del mal y el principio del bien. Esto implica que el ser humano debe llevar a cabo una lucha diaria contra su inclinación hacia el mal, una lucha que implica hacer uso de su razón y tomar como máximas aquellos principios justos cuyo fin más extremo sea la felicidad tanto suya como la de sus semejantes. Resulta de gran importancia destacar que en su obra La religión dentro de los límites de la sola razón (1793), Kant dedica dos epígrafes a la disposición originaria de la naturaleza humana al bien y al mal. En referencia a la primera, distingue tres elementos que creemos importante resaltar, estos son: la disposición a la animalidad, a la humanidad y a la personalidad (Kant, 1793: 42). En primer lugar, la animalidad se refiere a una actitud del ser humano en la que no interviene la razón, es una tendencia a la propia conservación y propagación de la especie, a lo que hay que sumar el instinto social de vivir en comunidad con otros seres humanos. Cuándo estas disposiciones se desvían muchísimo de su fin natural dan lugar a los vicios animales como la intemperancia, la lujuria y la anarquía. En segundo lugar, la humanidad se refiere al quererse a uno mismo/a en opinión de los demás, si esto deriva en querer superar a los otros, puede fomentar los vicios de la envidia y la rivalidad. Y por último, en cuanto a la disposición a la personalidad, cabría señalar que se trata de respetar la ley moral como móvil suficiente para formar el carácter propio desde el libre albedrío.

En cuanto a la propensión al mal, entendemos por propensión «el principio subjetivo de la posibilidad de una inclinación, de un apetito habitual» (Kant, 1793: 44). Consecuentemente, cuando hablamos de una propensión al mal moral nos estamos refiriendo a que existe la posibilidad de que nos desviemos de las máximas de la ley moral. Dentro de esta posibilidad Kant distingue tres grados de desviación en los que puede incurrir el individuo: fragilidad, impureza y maldad. Este último, que sería el mayor grado de mal, se refiere a la propensión del albedrío a máximas que supeditan el móvil fundado en la ley moral a otros móviles no morales. En esta línea, Kant señala que la inclinación que cada ser humano tiene al mal, resulta subjetivamente necesaria, y la denominará como «mal radical o innato». Se trata de un principio que no se puede situar ni en la sensibilidad de la persona ni en una perversión de su moral. No obstante, cuando el ser humano hace de los móviles de su sensibilidad, su máxima sin tener en cuenta la ley moral, sería moralmente malo. Pero esto no quiere decir que sean los móviles que el ser humano adopta como máxima lo que diferencia a un individuo bueno de uno malo, sino la tergiversación de dichos móviles al tratar de adoptarlos como máxima suya (Kant, 1793: 51). 
Pero entonces, ¿qué motivación debe tener el ser humano para obrar conforme a la ley moral? Si partimos de la idea del sujeto como ser moral, y por tanto como ser libre, vemos que éste no necesitaría de una idea de ser superior para obrar conforme a la moral. Es decir, la razón pura práctica que posee el ser humano se basta a sí misma (Kant, 1793: 23) y no precisa de nada más. Por tanto, quien desee desarrollar su moralidad no deberá buscar nada fuera de sí mismo/a, como sería en este caso la existencia de un Dios que justificase sus acciones, porque todo lo que provenga de fuera nunca va a compensar su falta de moralidad. Y es que toda razón de la acción que no sea la del cumplimiento del deber por el deber, hace del mismo individuo "una persona ruin» (Kant, 1973: 24). Por tanto, no se debe caer en el error de fundar la religión en una especie de medio para que un ser superior "perdone» esa carencia de bondad que le caracteriza, sino que la religión moral va a servirle de guía para actuar conforme al deber.

Por otra parte, cuando nos referimos al origen del mal, podemos hablar del origen temporal o del moral. Sin embargo, el primero carecería de importancia en la tarea que nos ocupa, ya que al tratarse de un carácter moral propio, debemos abstenernos de buscarle todo origen en el tiempo. Porque la maldad persiste aún en el tiempo y además, no resulta tan importante el tiempo en que se cometió esa acción malvada como las razones que motivaron dicha conducta en el individuo. Sin embargo, si nos remontamos a la Sagradas Escrituras podemos observar cómo se sitúa el origen del mal en un tiempo anterior al ser humano, encarnado en una especie de espíritu externo a éste que le coloca en un estado de inocencia primigenia. Se trataría de algo así como de señalar que el primer ser humano era un ser inocente y puro, que seducido por una especie de espíritu maligno, acabó por caer en la práctica del mal, pero que al tratarse de un ser racional, aún trnía la oportunidad de mejorar. No obstante, esta explicación no nos debe valer porque, según la filosofía de Kant, nosotros nos vamos a representar a dicho ser en pleno uso de su razón, por tanto, no se trataría de un ser "radicalmente corrompido" (Kant, 1793: 58), su inocencia no podría suplir a su libertad de hacer uso de la razón para apartarse del mal.

En definitiva, para comprender la disposición al mal de los seres humanos, debemos partir no de una inocencia connatural, sino de una «malicia del albedrío que nos lleva a adoptar nuestras máximas de un modo contrario a la originaria disposición moral» (Kant, 1793: 65). En este aspecto, la mejor manera de compensar ese déficit estriba en la ley moral, que supone por sí misma un móvil completo. Pues quien tome la ley moral por máxima será un ser humano moralmente bueno, ya que será un referente moral al cumplimiento del deber. 
En la reflexión antropológica siempre ha tenido un gran interés la cuestión de la bondad/maldad del ser humano, a pesar de haber posiciones distintas y muy contradictorias, Kant «detecta con tristeza una presencia del mal en la acción humana» (Cabedo, 1997: 42). No obstante, reconoce que para suplir este hecho, el ser humano, mediante un constante proceso de mejoramiento moral, puede acabar siendo bueno. Así pues, si lo que deseamos es retornar a la primitiva disposición al bien del ser humano, debemos adoptar por nuestra máxima los móviles contenidos en la ley moral. Será nuestra disposición al bien la que nos convierta en seres buenos. Para conseguir este mejoramiento debemos llevar a cabo un cambio de costumbres, lo que conlleva inevitablemente la formación de un nuevo carácter. Para esto, el ser humano deberá llevar a cabo una revolución racional propia, que le llevará a convertirse en un sujeto racional predispuesto al bien. Esto supone no admirar los actos virtuosos desde fuera, sino cumplir el deber, que constituye el orden moral.

La idea del mejoramiento personal implica acudir a la religión moral, que es la que verdaderamente insta a dicha mejora, ya que es la que nos hace conscientes de que para ser mejores debemos decidir y actuar según la ley moral; y no como en las religiones que pretenden la mejora a partir de pedir favores a Dios y que cae en falsos cultos que sólo promueven las supersticiones y el fetichismo. Y es que «la conducta perezosa y pusilánime que desconfía por entero de sí y que espera la ayuda exterior, debilita todas las fuerzas del hombre y lo hace indigno de esta misma ayuda» (Kant, 1793: 69). La religión moral supone en esta línea, el mejor modo de guiarnos para la consecución del bien. Para esto, en la fe estatutaria se echa mano a la personificación del principio del bien en el mundo, a la idea de un ser que representaría la obligación moral en sí misma, aquél que encarnase en su figura el ideal de la Humanidad y que en el caso del cristianismo, se trataría del Primer Maestro que encarnó dicho modelo en la tierra. El ideal de una Humanidad agradable a Dios es el de la perfección moral, aquella persona que se considere digna de la complacencia divina será quien se guíe según su fidelidad permanente al prototipo de la Humanidad, aún viéndose sometido a tentaciones y sufrimientos (Kant, 1793: 74).

Sin embargo, existe aquí un error generalizado y es que para convertir la idea de un ser humano moralmente grato a Dios en un modelo para guiar nuestra conducta, no se hace necesaria la experiencia, ya que todo individuo debe ser un ejemplo de aquella idea, "su existencia en el alma humana es ya de por sí lo suficientemente inefable como para que no se tenga necesidad de admitir, además de su origen sobrenatural, su personificación en un hombre particular» (Kant, 1793: 75). Y es que un hijo de Dios que contase con gran pureza de su voluntad de forma congénita supondría muy lejano a las personas de carne y hueso, ya que no podría ser un ejemplo a seguir para las personas de a pie.

Como señala el mismo Kant, las dificultades que encontramos a la hora de concebir una persona que encarne por sí sola el modelo de bondad y 
pureza divina se dividen en tres. La primera se refiere a que la distancia entre el bien que debemos realizar y el mal del que partimos es inmensa y la dificultad reside en saber explicar cómo la intención de nuestros actos puede suplir a las obras mismas, siempre deficientes. La segunda dificultad atañe a la felicidad moral, porque cuando alguien se propone andar el camino de la bondad y la ley moral pueden ocurrir dos cosas. Puede ser que aquel que ha hecho propósitos de hacer el bien y siempre ha caído en las tentaciones, haya podido comprobar que la corrupción atañe directamente a la raíz de la conducta humana y no tendrá por seguro conseguir una buena conducta en el futuro, por eso será probable que deje de intentar hacer el bien en sus acciones. Sin embargo, alguien que haya obrado siempre adecuadamente sabrá que le espera en el futuro una felicidad incondicional. En tercer y último lugar, la idea de que «todo ser humano en el juicio de toda su vida aparece ante una justicia divina como reprobable» (Kant, 1793), nos transporta a una especia de deuda original que recae en el hecho de que empezó por el mal y es imposible eliminar su culpa, por tanto, tiene una deuda original con Dios en referencia a su mal radical.

Por tanto, la conversión del ser humano con su mal radical hacia el bien supone una especie de transformación de su propia naturaleza, en su nueva actitud el individuo es otro, moralmente hablando. $Y$ es que el ser humano es el juez más severo de sí mismo y no debe esperar ser juzgado por un Ser Superior en el más allá; sino que debe ser él mismo el que en cada acto que vaya a desarrollar delibere acerca de la corrección o no del mismo para seguir adelante con él, o por el contrario, acabar con su mala conducta. En definitiva, para acabar diremos que «la dificultad y, al mismo tiempo, la necesidad de llegar a una buena conducta es lo que, según Kant, da origen a la religión y la justifica» (Quintana Cabanas, 1989: 8). Por eso no debemos perder de vista que la religión moral es la única plenamente universal, ya que es la que guía la buena conducta de todos los seres humanos, sin distinciones de razas, etnias, sexos, etc. 


\section{SEGUNDA PARTE: ANTROPOLOGÍA DE LA RELIGIÓN}

\section{La Iglesia universal y las Iglesias particulares}

Según Kant, existe una Iglesia universal que tiene carácter moral y se funda sobre la fe religiosa pura, es decir, una fe racional; además, existen las Iglesias particulares cuyos principios de conducta adoptan la forma de una fe estatutaria. Por lo mismo, puede decirse que "hay varias Iglesias y creencias, no pudiendo afirmase, en cambio, que haya varias religiones» (Kant, 1793 :18). Así pues, la radical diferencia que existe entre ambas es que las segundas sirven de medios para la consecución de la Iglesia universal, fundada en la moralidad y la fe racional pura.

Cualquiera de estas iglesias estatutarias, entre las que se encuentra también el cristianismo, serían entendidas como un medio provisional para llegar un día a la religión moral pura, que prescinde de los dogmas. En consecuencia, si tomamos como ejemplo el cristianismo, ya que Kant lo concibe como la Iglesia particular que más se ha acercado en sus principios rectores a la Iglesia universal, vemos que una Iglesia particular vale como recurso que ayuda al cumplimiento de la moral. El problema reside en el momento en que dicha iglesia quiere constituirse en un fin en sí misma, dando lugar a la superstición (Quintana Cabanas, 1989: 18). Es decir, cuando las iglesias estatutarias promueven prácticas que se desvían de la moral y la razón, derivan en falso culto que pueden provocar fanatismo e intolerancia religiosa entre los creyentes, cualidades que atentan contra la consecución de la paz en el mundo, hecho que debe ser el fin último de toda religión.

Para Kant, la auténtica religión se reduce a los límites de la razón (Cabedo, 1997: 46), y es que la verdadera religión no debe encerrar otra cosa que leyes morales. Porque ésta nos ha de llevar al conocimiento de todos los deberes morales del ser humano como mandamientos divinos (Kant, 1793: 129). Es decir, la divinidad está fundamentada en la razón y su ejercicio, partir del principio inverso supone partir de la idea de Dios para fundamentar la moral, y esto es inaceptable desde un punto de vista racional. Por tanto, el recurso a la divinidad tiene como objetivo «la potenciación del progreso moral» (Cabedo, 1997: 47) y no debe concebirse de un modo distinto a éste. Como acabamos de comentar, Kant reconoce que el cristianismo y otras religiones han contribuido a lo largo de la historia a mantener el orden moral, sin embargo, esto ha ocurrido en tanto en cuanto se han hecho cargo de la responsabilidad moral de las personas. En el mismo momento en que se ha dejado de lado la responsabilidad moral, se ha caído en la superstición cultural dando lugar a enfrentamientos y guerras de religión.

Por otra parte, cabe tener en cuenta que una religión de la razón necesita doctores, porque si se deja a la razón para que cada individuo la siga según sus propias consideraciones, no se podría llegar nunca a la facticidad de una Iglesia como asociación universal de todos los seres 
humanos. Por tanto, las leyes cognoscibles por la propia razón deben ir revestidas de ciertas disposiciones estatutarias con autoridad, o como Kant diría, con prestigio legislativo. No obstante, no hay que olvidar que no es la observancia de los deberes eclesiásticos externos estatutarios los que pueden hacer al ser humano agradable a Dios, sino únicamente la actitud moral pura del corazón. Dichos deberes serían los siguientes: cumple tu deber no teniendo otro móvil que no sea la estima inmediata del mismo; ama a Dios y ama a tu prójimo como a ti mismo. En cuanto a las recompensas por haber cumplido con nuestro deber en este mundo, diremos que aquellos que cumplieron por la esperanza de la recompensa, recibirán por lo mismo una recompensa diferente que aquellos que hacen el deber por razón de sí mismo.

Por último, cabe destacar que en la paz radica el «bien supremo de la Humanidad» (Cabedo, 1997: 36), por esta razón los esfuerzos desencadenados desde las Iglesias particulares deben ir encaminados a su consecución. La voz de la razón es la que determina el estado de paz como el bien supremo para la Humanidad, en esta línea, Kant propone una especie de alianza donde un pueblo ilustrado, autoproclamado en república, pueda dar ejemplo a los demás pueblos y cesen las disputas. Así pues, se sostiene que «deben ser abolidos todos los planteamientos que incluyan carácter predominantemente amoral o inmoral» (Cabedo, 1997: 37), lo que quiere decir: todas las iglesias particulares cuyos dogmas se basen en el falso culto y la superstición.

\subsection{El peligro del falso culto}

Cuando hablamos del falso culto que se da dentro de las Iglesias particulares, se debe tener en cuenta el antropomorfismo del Ser Superior como algo sumamente peligroso en lo que respecta a nuestras relaciones prácticas con la voluntad divina y a nuestra moralidad. Y esto es así porque cuando antropomorfizamos la figura de Dios o de su descendiente directo en una persona concreta, corremos el riesgo de representarnos a Dios como aquel del que esperamos que perdone todos nuestros pecados, o aquel al que nos será más fácil complacer. En este orden, el falso culto da comienzo cuando el propio hombre no se percata de que "para pertenecer al reino de Dios le basta con llevar a cabo una conducta moral pura y cree que servir a Dios es tributarle un culto" (Kant, 1793: 16). Sin embargo, aquello que más acerca al individuo a un Ser Superior es la conducta que sale de su interior no motivada por fines externos, sino por razón del propio deber racional. Así pues, la idea de que el sujeto puede hacerse agradable a una deidad a través de ciertas prácticas como la oración, los rituales o la creación de templos no hace más que acrecentar las diferencias entre creencias y promover así los odios e incomprensiones entre los seres humanos. Y es que «no hay que tributar a Dios un culto externo ritual, pues Dios nada puede recibir de nosotros» (Quintana Cabanas, 1989:11), somos nosotros los que podemos recibir de él las guías para actuar conforme al 
deber moral. Así, el punto de partida no está en lo que Dios ha hecho por nosotros sino en lo que nosotros hemos de hacer por Dios.

Por otra parte, los sacrificios han sido históricamente la mayor forma de expiar los propios pecados y rendir culto a Dios. No obstante, al igual que otros rituales, resultan ser un engaño de gran envergadura al intentar aproximarnos a Dios, ya que «todo cuanto el hombre cree poder hacer aun, además de observar una buena conducta, para hacerse agradable a Dios es mero delirio religioso y falso culto de Dios» (Kant, 1793: 174). Así pues, atendiendo a la deficiencia moral con que nace todo ser humano, aquél que actúe con auténtica entrega a la práctica conforme el deber, podrá esperar con tranquilidad que la suprema sabiduría habrá suplido de algún modo lo que él no ha podido hacer. Sin embargo, aquél que no ha actuado en base al deber y se dedica a la aceptación, la confesión y la glorificación de todo lo que ha sido objeto de revelación, cae en el falso culto a Dios y no puede esperar haber alcanzado un nivel óptimo de moralidad en sus acciones. En este aspecto, la oración es una actividad nula si su objetivo reside en acceder a la divinidad mediante un acto que en sí no consiste más que en la expresión de deseos y pretensiones del mismo individuo. Pero si se encamina a estimular al grupo de creyentes para poder traducir en la realidad, entre todos, la práctica moral, puede resultar de gran provecho para la Humanidad. A pesar de esto, inicialmente, el culto y la oración carecen de sentido si son concebidos como actos externos al ser humano provocado por motivos no morales.

Por otro lado, los milagros son algo común en el devenir de la fe estatutaria. Aunque los seres humanos creen teóricamente en ellos, en la práctica no los admiten. En esta línea, los milagros serían «acontecimientos ocurridos en el mundo en los cuales las leyes que rigen los efectos derivados de las causas nos son absolutamente desconocidas" (Kant, 1793: 97). Existen dos tipos, los demoníacos y los divinos, los primeros son los que resultan más incompatibles con el uso de nuestra razón. Además, se ha de hacer mención a los misterios, como algo sagrado que cada individuo en particular puede sin duda conocer, pero no darlo a conocer públicamente, este es, comunicarlo universalmente (Kant, 1793: 145). Es imposible determinar a priori si existen o no los misterios, por eso hemos de tener en cuenta que la religión moral universal es una religión sin misterios. Los únicos misterios que podemos admitir desde las teorías de Kant, son tres: "la vocación a formar una comunidad humana moral, la satisfacción por las propias culpas mediante unos méritos ajenos y la predestinación» (Quintana Cabanas, 1989: 11).

Si se considera que la fe estatutaria es esencial al culto divino, si se hace de ésta la condición principal de que Dios pueda complacerse es un delirio religioso, existen riesgos de caer en falso culto (Kant, 1793: 171), una pretendida manera de adorar a Dios con la cual se procede de un modo contrario al auténtico culto que ese mismo ser superior exige como idea regulativa. En resumen, "piensa Kant que la confianza en obtener fácilmente el perdón de las propias culpas contando con el recurso a unos méritos ajenos o a ciertos ritos viene a facilitar o provocar los vicios y las 
malas obras» (Quintana Cabanas, 1989: 15). Esto deriva en el falso culto y la superstición, ya que hace creer a los seres humanos que uno puede acercarse a Dios o incluso hacérsele agradable mediante la práctica de ciertos ritos. Porque la religiosidad no es algo externo al individuo, sino que supone comprometerse voluntariamente desde la libertad a recorrer el camino de la moralidad.

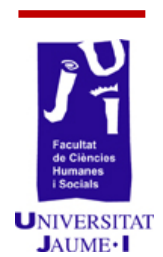

\section{El cristianismo: un ejemplo de fe estatutaria}

En sus escritos, Kant nos habla sobre todo del judaísmo y el cristianismo. En cuanto al primero se refiere, el filósofo señala que la fe judaica no puede ser identificada con la fe eclesiástica porque no es propiamente una religión, "sino la simple asociación de una multitud de personas que, por pertenecer a un mismo linaje especial, vinieron a formar una comunidad pública regida por leyes puramente políticas» (Kant, 1793: 133). Es decir, con el judaísmo se formó una comunidad política y no una comunidad moral, ya que la fe religiosa nunca fue un elemento constitutivo de la legislación judaica.

En esta línea, el cristianismo nació a partir de la doctrina judaica, pero de un judaísmo que ya se había mezclado con la fe religiosa a consecuencia de las doctrinas morales que se habían introducido en él. Aún así, debemos destacar una diferencia entre ambas, y es que como fe histórica, se encuentran basadas en libros, algo que requiere para su garantía un público erudito que pueda leer o controlar dichos escritos para hacérselos llegar a los creyentes. Sin embargo, desde el nacimiento del cristianismo hasta el momento en que constituyó ya de por sí un público erudito, dicha religión tiene un periodo obscuro. Ejemplo de esto son «las exaltaciones místicas en la vida de los eremitas y de los monjes, junto a la ponderación de la santidad del celibato y cómo unos pretendidos milagros relacionados con lo anterior oprimieron al pueblo, bajo una ciega superstición, con pesadas cadenas» (Kant, 1793: 138). Por tanto, a pesar de que el filósofo reconoce en el cristianismo una fe eclesiástica que promueve la transición hacia la verdadera Iglesia universal basada en la fe moral, también sabe reconocer que existen en sus orígenes épocas oscuras de falso culto.

A pesar de lo comentado anteriormente, el cristianismo fue la primera doctrina de fe en establecer la fe racional y moral de forma pública alrededor de todo el mundo. Así pues, debemos tener en cuenta que como Iglesia particular que camina hacia la universal, deberá tener deberes índole estatutaria y racional. El riesgo recae en la comprensión de la Escritura como revelación, es decir, los eruditos son los que comprenden la Escritura (los clérigos), pero puede ocurrir que estos lleven tras suyo una masa de ignorantes que no lleguen a comprenderlas, estos deben garantizar que mediante el honrar la razón humana universal como el principio que debe imperar en la religión natural, la doctrina revelada cultivada será un simple medio para hacer asequible a los ignorantes dicha creencia. 
En esta línea, la diferencia entre judaísmo y cristianismo en cuanto a la interpretación de la Sagrada Escritura estriba en que en el segundo, la doctrina es concebida como salida directamente de la boca del Primer Maestro en forma de una religión no estatutaria sino moral y al hallarse así íntimamente vinculada con la razón, gracias a ésta pudo propagarse por sí misma con la mayor seguridad. A partir de la figura del Maestro del Evangelio, se hizo visible la dignidad de ser ciudadanos de un Estado divino, al mismo tiempo que se les preparó para que estuvieran dispuestos a las mayores tribulaciones y sacrificios. En este aspecto, la aparición del Anticristo junto al anuncio de la proximidad del fin del mundo pueden "cobrar ante la razón una significación simbólica, y dicha proximidad, concebida como un acontecimiento imprevisible de antemano, expresa muy bien la necesidad de estar siempre preparados para ella» (Kant, 1793: 143). $Y$ es que una religión como el cristianismo, siempre expuesta a las continuas arbitrariedades de los intérpretes adopta dos principios para caminar hacia la verdadera religión moral.

El primero es una gran discreción en referencia a la actitud con respecto a las revelaciones. El segundo, insta a que la historia sagrada sea siempre enseñada y explicada como refiriéndose a lo moral, porque la verdadera religión ha de centrarse en aquello que debemos hacer nosotros para hacernos merecedores de Dios, y no al revés. Kant no niega la posibilidad interna de una revelación, lo que dice es que el hombre no estaría en grado de poder entenderla como tal. Por eso si existe un documento como la Biblia que ha ejercido y ejerce una gran influencia sobre el género humano, y que se remite a una revelación de Dios en la historia, tendremos que interpretarle desde una perspectiva racional. El criterio supremo para la interpretación de los textos sagrados será entonces, el mismo que el fin de toda religión de razón que consiste en «la mejoría moral del hombre» (Sánchez Zermeño, 2004: 7).

En conclusión, toda religión, incluso aquella que es revelada, debe tener también principios de la religión natural, ya que sólo mediante la razón puede introducirse la revelación en el concepto de una religión (Kant, 1793: 160). Así pues, consideraremos a una religión revelada como una religión natural y al mismo tiempo erudita. 
IX. Una comunidad pública moral

El ser humano se encuentra a lo largo de su vida en continua lucha contra el mal para poder llegar a ser verdaderamente libre. Sin embargo, es en su convivencia con otros seres humanos cuando mayor riesgo corre de corromper su conducta y caer en malas costumbres. Por esta razón, «el principio del bien no es alcanzable de otro modo que con el establecimiento de una sociedad regida por leyes de la virtud y fundada para las mismas» (Kant, 1793: 102). Fundar una comunidad pública moral regida por leyes morales constituye lograr una fuerza unificada para los seres humanos, para poder resistir a las acometidas del principio del mal. Pero esta es una empresa que parece quedar grande a la sabiduría que pueda hallarse en el individuo, debe ser Dios mismo quien sea el autor de su propio reino. Los seres humanos, serían en todo caso, los autores de su organización y administración. Así pues, la religión de la pura razón tendrá como ministros suyos a todos aquellos que piensen el bien.

Una comunidad pública moral tiene que ver con el ideal de conjunto de todas las personas, una comunidad que permite al sujeto salir de su estado de naturaleza moral, donde se haya constantemente asediado por el mal y pasar a un estado político-civil. Porque el ser humano, como tal, tiene un deber con el género humano, un deber que presupone la idea de un ser moral superior que hará que las fuerzas de por sí insuficientes de los individuos lleguen a unirse en un resultado común (Kant, 1793: 106). El hecho de formar una comunidad pública de personas permite una conciencia de que «el bien moral supremo no llega a lograrse por el solo esfuerzo de la persona individual en pro de su propia perfección moral, sino que exige la unión de todas las personas formando un conjunto que tienda a este mismo objetivo» (Quintana Cabanas, 1989:17). Se crea así lo que será un pueblo de Dios guiado por leyes morales.

Se debe diferenciar entre comunidad jurídica y comunidad moral. En la primera, el pueblo es su legislador propio, con lo que se compatibiliza la libertad de todos con la de cada uno, mientras que en una comunidad moral se fomentan las leyes de la moralidad más que la legalidad de los actos, la forma no importa tanto como el contenido de los actos. En esta línea, la verdadera iglesia visible es aquella que representa el reino moral de Dios sobre la tierra, en cuanto éste se hace posible tratándose de seres humanos (Kant, 1793: 109). Para construir una verdadera iglesia, ésta se debe basar en la universalidad, la cualidad (asociarse en base a unos móviles morales), la relación bajo el principio de libertad conformando una república y la inmutabilidad de su constitución.

La dificultad de llegar a conformar una comunidad pública moral está en el reconocimiento de que lo único que Dios exige a sus súbditos es que lleven a cabo una conducta moralmente buena, sin embargo, los seres humanos tardan en convencerse de esto, y llevan a cabo las acciones por 
cuestión de forma (leyes) y no de contenido (móviles morales). Y esto puede provocar que tardemos más en llegar a esa creación de la comunidad moral, una de las claves se encuentra en que «toda religión consiste en que consideremos a Dios como el legislador a quien todos han de venerar» (Kant, 1793: 112). El principal error reside en saber cuál es la forma verdadera en la que Dios desea ser honrado, los seres humanos suelen errar y no ven que es sólo con el entero cumplimiento de la moral, del deber por el deber, la única forma con la que puede honrar a un Ser Superior.

En esta línea, la idea de la creación de una comunidad pública moral, cuyo camino vendrá marcado por la religión universal, es decir, por la puesta en práctica por parte de los seres humanos de su principio moral; está estrechamente relacionada con la paz perpetua como fin último de la Humanidad. No podemos acabar pues, sin señalar que para Kant «el desarrollo constante de la libertad de la Humanidad adquiere significado empírico en el desarrollo de la legalidad, que ha de trascender los límites de los Estados para acabar extendiéndose en las relaciones interestatales de los pueblos hasta formar una sociedad cosmopolita» (Gil, 2007: 8).

\section{Conclusiones}

Como se ha visto a lo largo de todo el escrito, para Kant existe en el ser humano una inclinación al mal y otra al bien, sin embargo, no es esta cualidad en sí misma la que convierte al individuo en bueno o malo sino el decidir libremente si convierte en su máxima el principio del mal o el del bien. La cuestión es que existe en la especie humana una debilidad que hace que se acabe convirtiendo al mal en la máxima de nuestras acciones. Dicha deficiencia promueve en nosotros el deseo de mejoramiento que el nacimiento de la religión para guiarnos en nuestra mejora moral. Porque es la creencia eclesiástica lo que contribuye al cumplimiento de los deberes humanos como si fuesen mandamientos divinos.

Por otra parte, si el concepto de Dios «surge sólo de la necesidad de la razón de pensar como posibles las leyes morales, entonces la religión, fundada en la creencia resultante sólo podrá ser una única, que es moral» (Sánchez Zermeño, 2004: 6). Sólo la religión moral puede presentar la pretensión de universalidad, ya que las Iglesias particulares no pueden conseguirlo. Con lo que no nos debe interesar tanto saber lo que es Dios en sí mismo como lo que es para nosotros en calidad de seres morales. A partir de las Escrituras Sagradas o más bien, de sus lecturas e interpretaciones llevadas a cabo por eruditos, el ser humano fija leyes cuyo contenido ayuda a hacer mejores a los seres humanos. Aunque cabe tener en cuenta el hecho de que sólo la fe religiosa pura fundada enteramente en la razón terminará en ser la iglesia inmutable. 
En resumen, "sólo hay una religión valedora para todos los seres humanos y todos los pueblos, es decir, la religión de la razón moral» (Kant, 367), religión que «preconiza el advenimiento de un estado de paz perpetua fundada en una confederación de pueblos en forma de república cosmopolita» (Kant, 1793: 50).

\section{Bibliografía}

ARAmayo, R.R. (2001a): «Kant y la Ilustración», Isegoría, 25, Instituto de Filosofía del CSIC, Madrid, pp.293-309.

- (2001b): Immanuel Kant, Grupo EDAF, Ediciones Algaba, Madrid.

CABEDo, S. (1997): «Religión y paz en Kant», en MARTínez GuzMán, V. (eds.): Kant: La paz perpetua, doscientos años después, NAU Llibres, Valencia, pp. 45-51.

GIL, J. (2009): "Un aporte a la filosofía política desde la ética de Ludwig Feuerbach», en VV.AA.: Presente, pasado y futuro de la democracia, Universidad de Murcia, Murcia, pp. 213-220.

- (2007): «Aproximación antropológica a la filosofía de la Historia en Kant», Fòrum de Recerca, 12, Publicacions de la Universitat Jaume I, Castelló de la Plana.

Hotтols, G. (1999): Historia de la filosofía: del Renacimiento a la Postmodernidad, Cátedra, Madrid.

KANT, I. (1795): Sobre la paz perpetua, Alianza, Madrid, 2006.

- (1793): La religión dentro de los límites de la sola razón, PPU, Barcelona, 1989.

- (1785): Fundamentación metafísica de las costumbres, Encuentro, Marid, 2003.

- (1784): ¿Qué es la Ilustración?, Alianza, Madrid, 2007.

FeUerbaCH, L. (1841): La esencia del cristianismo, Ed. Sígueme, Salamanca, 1975.

Pérez Quintana, A. (1999): «Una disposición natural al bien», en Aramayo, R. y F. ONCINA (comp.): Ética y antropología: un dilema kantiano, Ed. Comares, Granada, pp.91-124.

QUINTANA CABANAS, J.M. (1989): «Introducción» en KANT, I.: La religión dentro de los límites de la sola razón (1793), PPU, Barcelona, pp.5-19.

Reverter BAÑón, S. (1996): Teoría filosófica de Europa, Nau Llibres, Valencia.

SÁNCHEZ ZERMEÑo, J. (2004): “Notas sobre ética y religión en la filosofía de Kant», Revista Digital Universitaria, vol. 5, no 11, DGSCA-UNAM, México.

SANTIAGo OropezA, T. (2004): "Kant y su proyecto de una paz perpetua», Revista Digital Universitaria, vol. 5, 11, DGSCA-UNAM, México. 

